\title{
EXPLORING VIRTUAL ENTERPRISES USING ACTIVITY THEORY
}

\author{
Ronald C Beckett \\ The Reinvention Network \\ Sydney, Australia \\ E-mail: rcb@reinvent.net.au
}

\begin{abstract}
From joint Industry - University research into the key success factors that sustain Virtual Enterprises (VE's), it has been observed that conditions for the establishment of a VE do not necessarily sustain it. Transactions that are valued by the participants, a balance between similarity and complementarity attributes of the participants and effective utilisation of time are seen as important sustaining factors. Different communication and ICT tools are utilised in different circumstances, and successful collaborations develop formal or informal "rules" underlying their operation. Considering such attributes helps us understand what happens within a successful VE, but not necessarily how. Two case studies describing long-standing collaborations - one relating to a manufacturing network, and the other to a professional virtual community are presented. A third case study relating to the development of ICT tools to be used in a VE is also presented. Activity Theory is used as a framework for discussion of the organisational attributes associated with these cases and how they operate. It is suggested that exploration of the nature of tools, communities etc is helpful in understanding VE operations, and applied at multiple levels, Activity Theory is also useful in understanding the evolution of those tools, communities etc.
\end{abstract}

Keywords Virtual enterprise, Activity Theory, Collaboration

\section{INTRODUCTION}

Network forms of organisation within large firms and inter-firm collaborations to form Virtual Enterprises (VE) are becoming more common as a means of competing more effectively in a globalised business world (eg Wiendahl, Englebrecht and Hamacher, 2001), but the success rate of some of these initiatives seems low (eg Marceau, 1999). From previous research into the key success factors that sustain such organisations, it has been observed that conditions for the establishment of a VE do not necessarily sustain it. Transactions that are valued by the participants, a balance between similarity and complementarity attributes of the participants and effective utilisation of time are seen as important sustaining factors (Beckett, Hyland and Sloan, 2003). Identifying common goals, establishing consistent ways to do business and successfully engaging with the external environment are seen as essential establishment factors (Marceau, 1999). Different communication and Information and communications technology (ICT) tools are utilised in different circumstances, and successful collaborations develop formal or informal "rules" underpinning their operation. There are a lot of factors that characterise a VE, potentially making comparison between difference instances and their design difficult as there would seem to be many contingent variables. In this paper we look at one approach, Activity Theory, that links attributes such as goals, tools and rules to consistently make such a characterisation. Two case studies describing long-standing collaborations - one relating to a manufacturing network, and the other to a professional virtual community are presented, along with a third case study describing an organisation set up just for one project: to conduct research into VE management methodologies and ICT tools. Activity Theory is used as a framework for discussion of the organisational attributes associated with these cases. It is suggested that exploration of the nature of tools, communities etc is helpful in understanding VE operations, and can be applied at multiple levels. In this latter context, Activity Theory is also useful in understanding the evolution of those tools, communities etc and how many intersecting networks might link together. 


\section{CASE STUDIES}

\section{A Manufacturing Network}

A study of Australian Toolmaking Innovations Pty Ltd (ATI) was carried out using both a questionnaire and interviews. Both the questionnaire and the interview structure built on previous work by Fulop and Kelly (1997). ATI is a virtual enterprise acting as a shopfront for a network of toolmakers, and it has been in existence about eight years. The primary goal of the ATI network was acquiring production orders from overseas. As the individual companies could not do this successfully due to their limited size, they formed a network to enter the export market as a larger entity. A secondary goal was to make the members stronger in the domestic market. The member firms in this network are all SMEs with between 20 and 100 employees. The driving force in the network was one of the two larger firms in the network. The latter is larger than the average firm because of activities other than toolmaking that are undertaken in that firm. As the age of the firms in the network varies from 19 to 35 years this can be regarded as a network of well-established firms. The managers interviewed described the domestic market growth potential of their toolmaking businesses as limited. Only the lead firm was expanding its factory floor for toolmaking. Some of the other network members have been downsizing their toolmaking businesses and have been looking for growth in other divisions. There are presently 5 firms in the network, all located in the southern Sydney region. Members find the area where the network members are located important mainly due to the ease of communication, and secondly for inter-firm transportation of products. There is a full time manager who operates independently, but is funded by the network partners. A Board of partners provides general direction and strategy. There have been three different managers to date.

The network members describe similarities in respect of the following characteristics:

- Product or service: All members do the same type of tooling (specifically plastic tooling) of high quality. Within that sector each has a speciality.

- Clientele or customers: The type of customer is similar for all members - the majority are automotive companies. Members have their own customer base and rarely have the same company as a customer. Customers all are demanding and want a wide range of services.

- Mode of operation: The members are the biggest toolmakers in the region and all very progressive in toolmaking. The mode of operation of the members is very much the same in the way that they all quote for orders, have similar operating methods (for example they all use $\mathrm{CAD} / \mathrm{CAM}$ ), and operate the same types of tools and machines. All members are privately owned companies.

- Territory or market: For the ATI network two types of market can be distinguished. These are the domestic market and the export market. All members operate in the same domestic market (Sydney, New South Wales, and Victoria). They have acquired their own overseas markets, although these are of a minor scale. The firms aimed to expand into the international market in collaboration using the network's capacity to win large orders.

- Relationships that developed between participants resulted in joint purchasing, sharing of resources and capacity to meet peak demands of long-term domestic customers, and in information sharing on new technologies.

The members have complementary capacity and machines. Every member has some specialization in a market sector. Members can share work with each other in confidence of quality and reliability. This gives the network a wide range of services to offer in tooling. Whilst the network has reduced its internal costs, and increased revenue by sharing some domestic market projects, the level of revenue hoped for from export work was not initially achieved. However, in recent years, following deployment of the full time Network Manager to China for lengthy periods, business has improved, and the VE is profitable in its own right on the basis of export orders. The experience has lead to the partners considering joint ownership of assets and new business ventures. Experience gained in collaboration has also resulted in one of the partners to call on the others to provide capacity in support of entry into a new market sector. 


\section{A Professional Virtual Community}

This network was studied using a questionnaire as a checklist to adopt a consistent approach to individual interviews. It is an informal innovation network of industrial designers, engineers, tool designers and tool manufacturers tending to specialise in the development of unique plastic product designs that might also require the development of unique production processes. Activities commenced in 1986 with just a few companies, and now it has about 15 participants distributed across five States in Australia. Each participant has less than ten employees, and the main criteria for participation seems to be demonstrated excellence in a specialisation, ease of collaboration and demonstrated contractually compliant performance. New business opportunities may be identified by any member who may then take the lead position for that project, or an opportunity may be referred to a more appropriately specialised partner for follow-up and leadership. The network arrangement enables members to offer turnkey product design and tooling packages to clients rather than just part of a package. The maintenance of a reputation for innovation and reliability is an important consideration for each individual participant, as in taking a lead position; they become interdependent on the others to maintain that reputation. The network itself is not a visible entity. Membership has changed over time as more specialisations have been added, and as difficulties have arisen with either ease of collaboration or contract compliance with past members. One of the members who has a strong orientation towards collaborative arrangements arising from prior experience in Europe appears to be the network champion, and he sets standards and protocols (eg everyone uses Microsoft Project software for project management). Although the network structure is informal, projects are formally operated with clearly defined roles and tasks. This network is based on accessing and sharing intellectual assets rather than physical assets, but it is in place to expand the market access of the participants rather than to share knowledge. Participants have noted some expansion of personal networks as a benefit. Technology intelligence and operational intelligence are seen as the main beneficial knowledge transactions. Some members of the network are considering establishing a more formal arrangement to develop their own products and brand.

\section{An International Research Project}

In January 2000 an industry-led international collaborative research project was launched by about 20 organisations in Australia, Europe and Japan to identify ICT tools and methodologies supporting inter-enterprise integration and collaboration in one-of-a-kind production. The project participants had some common interest in this kind of production, and there were various complementary skills amongst the participating organisations. The author was a participant in this project for some time, and this description draws on project publications. The project was completed in December 2002. Concepts of appropriate reference architectures, applications in distributed engineering, and sales and service, some issues related to planning and scheduling, and perceived partner benefits from participation were all presented in a final symposium (GLOBEMEN, 2002). Some of the project participants had worked together on a previous project, but some had not been involved in such an activity before. Some participants withdrew, and some new ones joined the team over the life of the project.

A comprehensive project implementation plan was agreed upon prior to project launch, with clear definition of work packages, lead partners for each work package, participant contributions to each work package, deliverables and progress milestone/reporting requirements. This had been a requirement of both the umbrella project organisation (www.ims.org) and one of the funding authorities. One of the participants established a web site with both public access and member-only access arrangements that formed a data repository for formally submitted project discussion papers and deliverable documents (http://globemen.vtt.fi). Each of the three geographic regions took a turn in providing a Secretariat function to facilitate the organisation of events, production of deliverables and progress reporting. Face-to-face workshops were held about every six months, with informal regional meetings in between. This provided a venue for participants to get to know each other better and for debate of different views. 
Tools and methodologies to support people networking in a global multicultural environment were sought with a focus on:

- Inter-enterprise information exchange and control

- Interaction with customers and users involving global product life-cycle management

- Optimisation of the delivery chain through inter-enterprise resource planning

- Distributed concurrent engineering

In the one-of-a-kind environment being investigated, a new virtual enterprise had to be constructed every time a large project was undertaken, and through the life of the project responsibility for interaction with the team and the client might change, for example as the emphasis moved from engineering design to after-sales support of a manufacturing plant constructed by the partners. This led to the adoption by the research team of a project life cycle oriented virtual enterprise reference architecture and to the use of some standard workflow analysis tools. Whilst the project focus was on the development of tools and methodologies, a number of human factors kept arising, such as how to develop trust between new partners when a new virtual enterprise was rapidly formed.

A formal process was established for measuring the success of the research project. Project performance indicators relating to deliverables and participation were developed, and individual partner success indicators were documented. During operation of the research project, benefits were noted from the requirement to report on success factors - participants were forced to reflect on what was being achieved and where it was leading; but it was also noted that the activity could be timeconsuming. The Participants were each asked to identify success indicators from the viewpoint of their individual organisations. This action, in effect, sought to establish what value-adding transactions were expected.

\section{DISCUSSION}

Some research related to VE's has focussed on ICT tools that facilitate sharing data and knowledge between remote partners. Other research has focussed on human factors such as trust. One approach being used to better understand human - computer interaction is to adopt the application of Activity Theory, and in the following discussion this will be applied to the three cases to illustrate the utility of such application.

Activity Theory (Vygotsky, 1978, Engestrom, 1987) is used in this paper to provide a framework for characterising the interplay of behaviours and tools that may be associated with successful Virtual Enterprise operations. A Virtual Enterprise is formed to do something as a collective activity that is achieved through the efforts of individual organisations and people. Activity Theory derives from studies of how people think in the context of undertaking an activity, and it is argued that their environment influences the way they think and act. In undertaking broad activities driven by some motivation, [Object] people decide to take an action [Subject] to achieve a goal requiring operations [Community] to be implemented through a series of tasks. How this is enacted is influenced by [Tools], [Rules] and the [Division of Labour]. Such a socially distributed activity system is illustrated in Figure 1. 


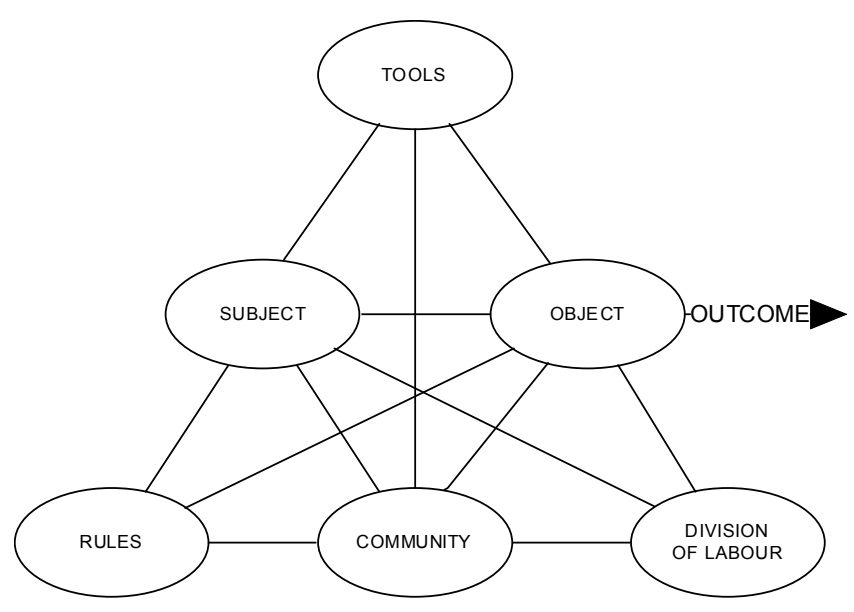

A MODEL OF WORK ACTIVITY

FIGURE 1:A SOCIALLY DISTRIBUTED ACTIVITY SYSTEM (FROM ENGESTROM, 1987)

In Table 1 below, each of the case studies has been mapped against each component of the system presented in Figure 1 to provide a holistic view of the cases.

The third case is different in that it was never intended to be an enduring arrangement, but its outcomes were intended to be used as tools for use in subsequent VE's. Kutti and Molin-Juustila (1998) used the notion of hierarchy to explore linked activity systems associated with each element of a greater system. For example, in the Third case, the topic "tools" is made the object, and illustrates how the development of ICT tools, and the rules, community etc associated with that object/motive can be described in the same way as the first two cases. In a similar way, the topic "Community" could be made the object to explore how single project Virtual Enterprises might be formed from a pre-existing network of potential partners, or the topic "Division of Labour" could be made the topic to understand how a project implementation plan might be developed. 


\begin{tabular}{|c|c|c|c|}
\hline $\begin{array}{l}\text { Activity Theory } \\
\text { Element }\end{array}$ & Manufacturing Network & Professional Virtual Community & GLOBEMEN International Research Project \\
\hline Object & $\begin{array}{l}\text {-The motivation is to access scale to remain } \\
\text { competitive as a strategic imperative }\end{array}$ & $\begin{array}{l}\text {-The motivation is to access complementary assets to } \\
\text { access broader market opportunities }\end{array}$ & $\begin{array}{l}\text { The motivation is to Identify and demonstrate } \\
\text { methodologies and ICT tools that will support the rapid } \\
\text { creation and operation of a global virtual enterprise to } \\
\text { undertake one-of-a-kind projects }\end{array}$ \\
\hline Subject & $\begin{array}{l}\text {-Action is through individual direct or indirect } \\
\text { project opportunities that utilise the toolmaking } \\
\text { knowledge of the partners and their supply chains }\end{array}$ & $\begin{array}{l}\text {-Action is through individual projects and cross- } \\
\text { referral opportunities generally related to specialised } \\
\text { plastics product design and development }\end{array}$ & $\begin{array}{l}\text { Action through research and development activities } \\
\text { undertaken by individual partners according to assignments } \\
\text { in the project implementation plan }\end{array}$ \\
\hline Community & $\begin{array}{l}\text {-Five established toolmaking Companies } \\
\text { undertaking individual projects either through the } \\
\text { VE as project manager, or by direct negotiation } \\
\text { between individual partners }\end{array}$ & $\begin{array}{l}\text {-14 to } 20 \text { informal participants establishing individual } \\
\text { projects involving some of them under the umbrella } \\
\text { of an individual lead company }\end{array}$ & $\begin{array}{l}\text { Nineteen participants from Australia, Europe and Japan, } \\
\text { some from business enterprises, some from research } \\
\text { institutes and some from universities. Some participants had } \\
\text { worked together before. Plenary meetings where individuals } \\
\text { could interact at the personal level were seen as important } \\
\text { to both team cohesion and to the debate of different views }\end{array}$ \\
\hline Tools & $\begin{array}{l}\text {-Partner project meetings and teleconferencing } \\
\text { facilitates interaction with remote clients } \\
\text {-CAD-CAM technologies support exchanges of } \\
\text { complex data }\end{array}$ & $\begin{array}{l}\text {-E-mail \& teleconferencing } \\
\text {-Microsoft "Project" } \\
\text {-CAD-CAM files } \\
\text {-Data transferred using STEP or PDF files }\end{array}$ & $\begin{array}{l}\text { E-mail used extensively. A server set up in Finland as a } \\
\text { repository for all; project data. Common formats for } \\
\text { deliverable documents determined. Common virtual } \\
\text { enterprise reference architecture and workflow modelling } \\
\text { tools adopted }\end{array}$ \\
\hline Rules & $\begin{array}{l}\text {-Formal VE Company structure requires Board } \\
\text { meetings, financial reporting etc } \\
\text {-Competency - based trust } \\
\text {-Relationship - based trust }\end{array}$ & $\begin{array}{l}\text {-Informal rules developed around: ----Competency - } \\
\text { based trust } \\
\text {-Contractual - based trust } \\
\text {-Relationship - based trust }\end{array}$ & $\begin{array}{l}\text { Project sponsors required standard forms of agreement and } \\
\text { a comprehensive project implementation plan. Key events } \\
\text { were scheduled to support direct interpersonal interaction } \\
\text { between the participants. Project success factors were } \\
\text { identified up front and mapped as the project proceeded. }\end{array}$ \\
\hline Division of Labour & $\begin{array}{l}\text { - ATI Manager acts as project manager, } \\
\text { determining who will do what tasks, depending } \\
\text { on task technical requirements and on available } \\
\text { capacity. The ATI Manager may contract outside } \\
\text { the network if necessary. The client may be } \\
\text { internal or external. }\end{array}$ & $\begin{array}{l}\text {-Lead Company with the client interface } \\
\text { responsibility determines who will do what, } \\
\text { depending on the competencies needed and the } \\
\text { availability of resources }\end{array}$ & $\begin{array}{l}\text { A project implementation plan defined who was doing what } \\
\text { and when. How things were done was left up to the } \\
\text { individual participants within the agreed rules. A co- } \\
\text { ordination / leadership function rotated between regional } \\
\text { partner groups }\end{array}$ \\
\hline
\end{tabular}

Table 1: A characterisation of two enduring Virtual Enterprises using Activity Theory element 
One issue observed by the author in previous research into network organisations is the need to find some common "language" and a consistent way of doing things between partners. It is suggested here that an Activity Theory based approach may be used to provide such a framework, and its application by the author to the development of a new network currently in the formative stages looks promising. Whilst potential industry participants first baulked at the expression "Activity Theory", once discussion of how the issues arising could be classified as relating to tools/community/rules etc, the concept was readily accepted.

Comparing the three cases using this framework, a number of similarities are evident: The object is to do something that the partners could probably not do on their own; subject action is via the efforts of individual partners working on well defined projects; the subjects engage a wider community in their background activities; there is a common use of IT enabling tools; there are formal or informal rules related to governance and partner expectations, and whilst there are different approaches to the division of labour, leadership in relation to its organisation is seen as important.

\section{CONCLUDING REMARKS}

Virtual Enterprises VE's) have few resources of their own, but draw on the combined resources of participants and their networks to achieve a shared goal. In previous work (Beckett, Hyland and Sloan, 2003) a study of the nature of transactions between the participants had proven helpful in understanding VE success factors. Other views (eg Vesterager, Larsen, Pedersen, Tolle, M and Bernus, 2001) consider project oriented reference architectures to define a framework for operations, or consider the actors, their resources and linkages (eg Todeva, 2001). These views help understand what is typically happening in the operation of VE's, but only partially reveal how this happens.

It is suggested here that the application of a socially distributed systems framework developed from the concepts of Activity Theory can help understand how different kinds of VE's operate, drawing out similarities and differences between them. In addition, an example of hierarchy is discussed drawing on the ideas of Kutti and Molin-Juustila (1998) illustrating how the framework can be used to describe how each element of the higher level one, such as tools, might be developed.

There is a lot of enthusiasm for the use of sophisticated ICT tools to enhance intra and interenterprise collaboration, and the case examples indicate they are important to the operation of a VE. But the success or failure of a VE is not generally due to the tools used. Success is related to a focus on common goals and people dynamics. Failure is more often related to a failure to develop sensible working rules, or poor division of labour, or failure to engage with the internal or external community. An Activity Theory approach supports the consideration of these factors. The author is currently using this approach in the design of new collaborations, with promising results to date.

\section{REFERENCES}

Beckett, R.C; Hyland, P and Sloan, T (2003) "Mapping Collaborative Transactions in Networks that Yield Business Benefits" Proc 19 $^{\text {th }}$ Annual IMP Conference, University of Lugano, Switzerland, 4-6 September (ISBN 82-7042-576-1)

Engestrom, Y. (1987) “Learning by expanding: an activity-theoretical approach to developmental research" Helsinki: Orienta-Konsultant

Foss, N. (1999) Networks, capabilities and competitive advantage. Scandinavian Journal of Management $15 \mathrm{pp} 1-15$

Fulop, L and Kelly, J. (1997) “A Study of Business Networks in Australia” Sydney: Australian Business Chamber

Hasan, H; Gould, E; Larkin, P and Vrazalic, L (Eds) (2001) "Information Systems and Activity Theory: Volume 2 Theory and Practice" University of Wollongong Press, Australia (ISBN 086418-6967)

Kuutti, K and Molin-Juustila, T (1998) 'System Support for 'Loose'Coordination in a Network Organisation: an Activity-Theory Perspective"in "Information Systems and Activity Theory: Tools in Context" Edited by H. Hasan, E.Gould and P.Hyland. University of Wollongong Press, Australia (ISBN 094712702 X) 
Marceau, J., (1999) 'Networks of innovation, networks of production and networks of marketing: collaboration and competition in the biomedical and toolmaking industries in Australia' Creativity and Innovation Management, Vol 8, No 1, March, pp20-27

Simmie, J., Sennett, J., Wood, P. and Hart, D. (2002) Innovation in Europe: A Tale of Networks, Knowledge and Trade in Five Cities. Regional Studies, vol 36 No 1 pp 47-64

Todeva, E., (2001) 'The explanatory power of network theory and its application to multi-national business relationships' Proceedings of APROS (Asia-Pacific Research in Organisation Studies), Hong Kong Baptist University, 3-5 December

Vesterager, J; Larsen, L.B; Pedersen, J.D; Tolle, M and Bernus, P (2001) "Use of GERAM as Basis for a Virtual Enterprise Framework Model” In Mo, J.P.T and Nemes, L (Eds) “Global Engineering, Manufacturing and Enterprise Networks", Kluwer Academic Publishers, The Netherlands, pp61-65

Vygotsky, L.S. (1978) "Mind and Society" Harvard University Press

Wiendahl, E.H, Englebrecht, A and Hamacher, O (2001) "From Single Enterprises to Complementary Networks" In Mo, J.P.T and Nemes, L (Eds) “Global Engineering, Manufacturing and Enterprise Networks”, Kluwer Academic Publishers, The Netherlands, pp 66-73 